\title{
Expression of miR-106 in endometrial carcinoma RL95-2 cells and effect on proliferation and invasion of cancer cells
}

\author{
XINGJUN LI ${ }^{1}$, XIANGHUA YI $^{2}$, CHUANDING BIE $^{3}$ and ZHEMIN WANG ${ }^{4}$ \\ ${ }^{1}$ Department of Clinical Laboratory, Chongming Branch Hospital, Affiliated Xinhua Hospital, School of Medicine, \\ Shanghai Jiaotong University; ${ }^{2}$ Department of Pathology, Tongji Hospital Affiliated to Tongji University, \\ Shanghai 202150; ${ }^{3}$ Department of Pathology, Suizhou Maternal and Child Health-Care Hospital, Suizhou, \\ Hubei 441300, ${ }^{4}$ Department of Orthopaedics, Chongming Branch Hospital, Affiliated Xinhua Hospital, \\ School of Medicine, Shanghai Jiaotong University, Shanghai 202150, P.R. China
}

Received March 27, 2018; Accepted May 24, 2018

DOI: $10.3892 / \mathrm{ol} .2018 .8926$

\begin{abstract}
Expression of miR-106 in endometrial carcinoma RL95-2 cell line and its effect on proliferation and invasion of cancer cells was investigated. miR-106 expression vector was constructed and transiently transfected into in vitro cultured RL95-2 cells of human endometrial carcinoma. Cells were divided into three groups including blank control cells (MOCK group), miR-106 transfection group (miR-106 group) and negative control group (siNC group).Reverse-transcription quantitative PCR (RT-qPCR) was used to detect the expression of miR-106. Proliferation and in vitro migration of RL95-2 cells were detected by MTT and scratch assay, and cell apoptosis was detected by flow cytometry. Compared with MOCK and siNC group, cell apoptosis rate was significantly decreased but cell proliferation rate was significantly increased in miR-106 group $(\mathrm{p}<0.05)$. In addition, cell migration and invasion ability was significantly increased in miR-106 group $(p<0.05)$. Overexpression of miR-106 can promote proliferation and inhibit apoptosis of endometrial cancer RL95-2 cells, and miR-106 may serve as a new target for the treatment of endometrial cancer in the future.
\end{abstract}

\section{Introduction}

Endometrial cancer is one of the three major malignant tumors in females and can occur in females of all age groups (1). Amant et al (2) showed that in 2016, 1.2 million new cases of endometrial cancer were reported worldwide, and endometrial cancers are the third most common malignancy that threatens

Correspondence to: Dr Zhemin Wang, Department of Orthopaedics, Chongming Branch Hospital, Affiliated Xinhua Hospital, School of Medicine, Shanghai Jiaotong University, 25 South Gate Road, Shanghai 202150, P.R. China

E-mail:wzr7bq@163.com

Key words: miR-106, endometrial cancer, RL95-2, invasion, proliferation, apoptosis the life and health of women. In recent years, incidence of endometrial cancer showed an increasing trend. In some European and American countries, incidence of endometrial cancer is the highest among all gynecologic cancers (3).

Due to the high incidence, clinical treatment of endometrial cancer has attracted increasing attention. Breakthroughs have been made in the treatment of this disease, and the majority of patients achieve promising prognosis after surgery, radiotherapy and chemotherapy (4). Plante et al (5) showed that the 5-year survival rate of patients with endometrial cancer is $\sim 85 \%$. However, tumor metastasis may also occur in some patients due to the lack of timely or improper treatment, seriously affecting patients' prognosis (6).

At present, the pathogenesis, migration and invasion of endometrial carcinoma are not clear. In recent years, miRNAs have become popular research objects. As a class of non-coding endogenous RNAs with a length of 17-23 nt, miRNAs can directly react with the 3'-UTR region of mRNAs to regulate the expression of target genes. miRNAs may show upregulated expression pattern to play oncogenic roles or show downregulated expression pattern to play a role as tumor suppressor genes (7-9). However, Zheng et al (10) showed that miR-106 promoted cancer cell proliferation in endometrial cancer. Therefore, our study aimed to further investigate the regulatory role of miR-106 in endometrial cancer with an expectation of providing references for the targeted therapy of this disease.

\section{Materials and methods}

Main materials. Human cervical cancer cell line RL95-2 was provided by the Department of Pathophysiology, Anhui Medical University. RT-PCR reverse transcription kit and miRNA isolation kit were purchased from Qiagen, Inc. (Valencia, CA, USA). Fetal bovine serum (FBS) was purchased from Gibco (Gibco; Thermo Fisher Scientific, Inc., Waltham, MA, USA). Tetramethyl azoline blue (MTT) and dimethylsulfoxide (DMSO) were purchased from Sigma-Aldrich (Sigma-Aldrich; Merck KGaA, St. Louis, MO, USA). Lipofectamine ${ }^{\text {TM }} 2000$ transfection reagent was purchased from Invitrogen; Thermo Fisher Scientific, Inc. 
Table I. Primer sequences.

\begin{tabular}{lll}
\hline Primers & \multicolumn{1}{c}{ mir-106 } & U6 \\
\hline Forward & 5'-CGGCTAAAGTGCTGACAGTGC-3' & 5'-GCTTCGGCAGCACATATACTAAAAT-3' \\
Reverse & 5'-GTGCAGGGTCCGAGGT-3' & 5'-CGCTTCACGAATTTGCGTGTCAT-3' \\
\hline
\end{tabular}

Annexin V-FITC/PI apoptosis kit was purchased from BestBio (Shanghai, China). The study was approved by the Ethics Committee of Chongming Branch Hospital, Affiliated Xinhua Hospital, School of Medicine, Shanghai Jiaotong University (Suizhou, China). Signed informed consents were obtained from the patients or the guardians.

Cell culture. Endometrial cancer cells RL95-2 were cultured in RPMI-1640 medium containing $10 \% \mathrm{FBS}$ at $37^{\circ} \mathrm{C}$ with $5 \%$ $\mathrm{CO}_{2}$.

Grouping. miR-106 primers were designed and synthesized by Shanghai GenePharma Co., Ltd. (Shanghai, China) (Table I). High-fidelity DNA polymerase was used to amplify miR-106, and the product was subjected to BamHI and HindIII digestion and was inserted into pcDNA3.1(-). Cells were divided into three groups including blank control cells (MOCK group), miR-106 transfection group (miR-106 group) and negative control group (siNC group).

\section{Methods}

Cell transfection. Digestion of cells using trypsin was performed and cells were counted. RL95-2 cells were seeded into 6 -well plates with $2 \times 10^{5}$ cells/well, followed by cell culture for $24 \mathrm{~h}$. Lipofectamine ${ }^{\mathrm{TM}} 2000$ was used for transfection according to the manufacturer's instructions when cell confluence reached $80 \%$. Expression of miR-106 was detected $48 \mathrm{~h}$ after transfection.

Reverse transcription-quantitative PCR (RT-qPCR). Tissues were mixed with TRIzol reagent and kept at room temperature for 30 min to extract total RNA according to the manufacturer's instructions. The total RNA was then reverse transcribed into complementary deoxyribose nucleic acid (cDNA) using cDNA synthesis kit (Biomiga Inc, San Diego, CA, USA). An ultraviolet spectrophotometer (Hitachi, Tokyo, Japan) and $1 \%$ denaturing agarose gel electrophoresis were used to test RNA quality. miR-106 reverse transcription was performed according to the manufacturer's instructions. miR-106 primers were designed and synthesized by Shanghai GenePharma Co., Ltd. (Table I). PCR reaction systems were prepared according to the manufacturer's instructions. PCR reaction conditions: $95^{\circ} \mathrm{C}$ for $10 \mathrm{~min}$, followed by 45 cycles of $95^{\circ} \mathrm{C}$ for $15 \mathrm{sec}$, $65^{\circ} \mathrm{C}$ for $30 \mathrm{sec}$ and $72^{\circ} \mathrm{C}$ for $30 \mathrm{sec}$. U6 was as an endogenous control, and data were processed using the $2^{-\Delta \Delta \mathrm{Cq}}$ method (11).

MTT assay. Density of RL95-2 cells was adjusted to $1 \times 10^{4} / \mathrm{ml}$ and cultured in 96 -well plates $\left(37^{\circ} \mathrm{C}, 5 \% \mathrm{CO}_{2}\right)$ for $24 \mathrm{~h}$. P-miR-106 and empty plasmid were transfected into cells using Lipofectamine ${ }^{\mathrm{TM}}$ 2000, and three replicate wells were set. After $72 \mathrm{~h}, 20 \mu \mathrm{l}$ of MTT reagent $(5 \mathrm{mg} / \mathrm{ml})$ was added to each well, followed by incubation for $2 \mathrm{~h}$. Supernatant was discarded with a pipette and $100 \mathrm{ml}$ of DMSO was added and shaken for 15 min. A microplate reader (Bio-Rad, Hercules, CA, USA) was used to measure the OD values at $450 \mathrm{~nm}$ and cell growth curves were plotted.

Flow cytometry. Cells in plates were rinsed with $2 \mathrm{ml}$ PBS solution, followed by incubation with $0.5 \mathrm{ml} 0.25 \%$ trypsin (without EDTA). After digestion, cells were resuspended to a density of $1 \times 10^{6}$ cells/ml, followed by incubation with apoptosis detection solution Annexin V-FITC at room temperature for $15 \mathrm{~min}$. After centrifugation at a speed of $375 \mathrm{x} g$ for $5 \mathrm{~min}$ at $4^{\circ} \mathrm{C}$, supernatant was removed, and cells were resuspended in $1 \mathrm{X}$ buffer. Finally, $10 \mu \mathrm{l}$ PI was added and flow cytometry was performed. The experiment was repeated 3 times.

Cell scratch assay. Cells were inoculated into 6-well plates $24 \mathrm{~h}$ after transfection, and three replicate wells were set. A $20 \mu 1$ tip was used to scratch cells when $90 \%$ confluence was reached. After washing with PBS 3 times, cells were cultured in $1 \%$ FBS in DMEM. This experiment was repeated 3 times.

Statistical analysis. SPSS 22.0 (IBM Corp., Armonk, NY, USA) statistical software was used for data analysis. The data are expressed as mean \pm SD. Comparison between groups was done using one-way ANOVA test followed by post hoc test (Least Significant Difference). Paired t-test was used for comparison between two groups. $\mathrm{P}<0.05$ was considered to be statistically significant.

\section{Results}

Expression of miR-106 after transfection. RT-qPCR results showed that the expression of miR-106 in miR-106 group was significantly higher than that in siNC and MOCK group $(\mathrm{F}=24.34, \mathrm{p}<0.01)$. There was no significant difference between siNC and MOCK group ( $\mathrm{t}=0.19, \mathrm{p}=0.86$, Fig. 1$)$.

Cell apoptosis. Flow cytometry was used to detect apoptosis of transfected cells. Apoptosis rate of miR-106 group after transfection was $3.08 \pm 0.74 \%$, which was significantly lower than that of the siNC group $(14.83 \pm 1.02 \%)$ and MOCK group $(13.17 \pm 0.94 \%),(F=147.20, p<0.01)$. There was no significant difference between siNC and MOCK group $(\mathrm{t}=0.03$, $\mathrm{p}=0.97$, Fig. 2).

Cell proliferation. After miR-106 was transfected into RL95-2 cells, results of MTT assay showed that there was no significant difference in cell proliferation rate between the two groups at $12-24 \mathrm{~h}(\mathrm{p}>0.05)$. After $48 \mathrm{~h}$, cell proliferation rate 


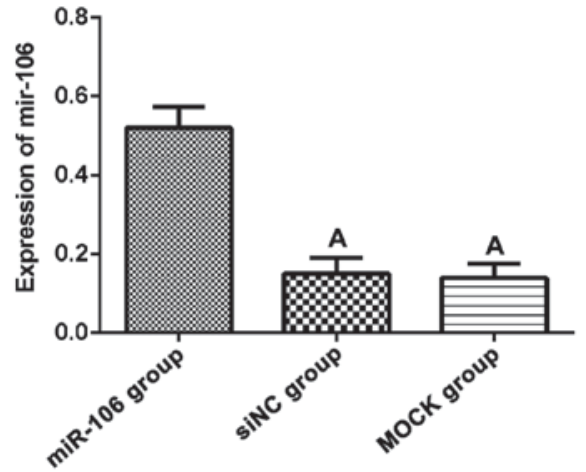

Figure 1. Expression of miR-106 in each group of cells. RT-qPCR results showed that the expression level of miR-106 in miR-106 group was significantly higher than that in siNC and MOCK group $(\mathrm{p}<0.05)$, but there was no significant differences between siNC and MOCK group ( $p>0.05)$. ${ }^{\mathrm{A}} \mathrm{P}<0.05$, compared with miR-106 group. RT-qPCR, reverse transcription-quantitative PCR.

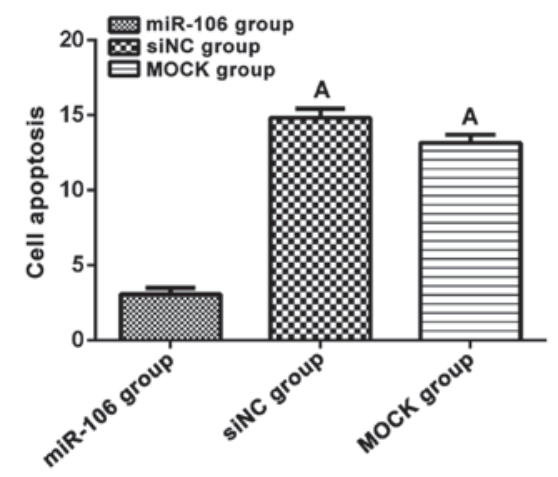

Figure 2. Cell apoptosis. Flow cytometry was used to detect cell apoptosis of each group after transfection. Cell apoptosis of miR-106 group was significantly lower than that in the other two groups $(\mathrm{p}<0.05)$. ${ }^{\mathrm{A}} \mathrm{P}<0.05$, compared with miR-106 group.

in miR-106 group was significantly higher than that in siNC group (p<0.05, Fig. 3).

Scratch assay results. By observing the width of scratched wounds under an inverted light microscope, cell migration of miR-106 group was significantly accelerated compared with siNC group $(\mathrm{p}<0.05)$.

\section{Discussion}

Endometrial cancer accounts for $\sim 10 \%$ of female malignancies, and onset age of this disease is becoming increasingly younger (12). Early stage of endometrial cancer has no obvious symptoms. Many patients were diagnosed at middle or advance stages and the best treatment timing was missed, which in turn leads to poor prognosis (13). Therefore, identification of gene targets and development of targeted therapeutic drugs for endometrial cancer is of great clinical significance. It has been proved that (14-16) proliferation, apoptosis, and invasion of cancer cells significantly affect the prognosis of patients. Proliferation, apoptosis and invasion of cancer cells is a multi-step and multi-factor involved biological process. In recent years, miRNAs have been shown to inhibit the translation of mRNA in almost all species $(17,18)$. Jonas and

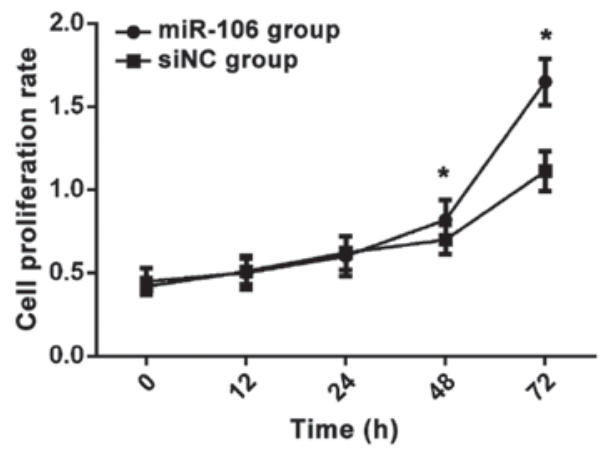

Figure 3. MTT proliferation curve. Results of MTT assay showed that there was no significant difference in cell proliferation rate between the two groups at $12-24 \mathrm{~h}(\mathrm{p}>0.05)$. After $48 \mathrm{~h}$, cell proliferation rate in miR-106 group was significantly higher than that in siNC group. After $72 \mathrm{~h}$, cell proliferation rate in miR-106 group was significantly higher than that in siNC group. ${ }^{*} \mathrm{P}<0.05$.

Izaurralde (19) demonstrated that miRNAs are involved in all biological processes in the body and have a strong regulatory role in normal cellular function (20). miRNAs participate in the occurrence and development of multiple tumors by regulating the proliferation, migration, apoptosis, and angiogenesis of tumor cells (20). Zheng et al (10) demonstrated that miR-106 promoted cancer cell proliferation in endometrial cancer. Therefore, we studied the effect of miR-106 on the proliferation and apoptosis of endometrial cancer RL95-2 cells with an expectation of providing references for targeted gene therapy.

miR-106 is located on chromosome Xq26.2 and consists of 23 nucleotides and is upmethyl thiazolyl tetrazoliumated in various tumors (21). In this study, we successfully constructed a miR-106 eukaryotic expression vector and successfully transfected it into endometrial cancer RL95-2 cells to detect its expression and biological functions. Expression of miR-106 in RL95-2 cells transfected with miR-106 was significantly higher than that in siNC and MOCK group $(\mathrm{p}<0.05)$. Wang et al (22) demonstrated that miR-106 enhances the self-renewal ability of glioma cells and the invasion ability of glioma stem cells by inhibiting the expression of matrix metalloproteinase-2 (TIMP-2). MMT assay and flow cytometry results also showed that miR-106 significantly affected apoptosis of RL95-2 cells, and miR-106 can effectively promote proliferation of endometrial cancer RL95-2 cells and inhibit cell apoptosis.

There are still deficiencies in this study. Due to the limited experimental conditions, in-depth investigation on the mechanism of the function of miR-106 in patients with endometrial cancer was not performed. Only in vitro experiments were performed and in vivo validation is lacking. Diagnostic and prognostic values of miR-106 for endometrial cancer were not evaluated.

In summary, miR-106 overexpression can promote the proliferation of endometrial cancer RL95-2 cells and inhibit cell apoptosis. miR-106 shows promise as a new target for the treatment of endometrial cancer.

\section{Acknowledgements}

Not applicable. 


\section{Funding}

No funding was received.

\section{Availability of data and materials}

The datasets used and/or analyzed during the present study are available from the corresponding author on reasonable request.

\section{Authors' contributions}

XL drafted the manuscript and contributed to cell culture. XY was responsible for cell transfection. $\mathrm{CB}$ and $\mathrm{ZW}$ helped with RT-qPCR and MTT assay. All authors read and approved the final manuscript.

\section{Ethics approval and consent to participate}

The study was approved by the Ethics Committee of Chongming Branch Hospital, Affiliated Xinhua Hospital, School of Medicine, Shanghai Jiaotong University (Suizhou, China). Signed informed consents were obtained from the patients or the guardians.

\section{Patient consent for publication}

Not applicable.

\section{Competing interests}

The authors declare that they have no competing interests.

\section{References}

1. Colombo N, Creutzberg C, Amant F, Bosse T, González-Martín A, Ledermann J, Marth C, Nout R, Querleu D, Mirza MR, et al; ESMO-ESGO-ESTRO Endometrial Consensus Conference Working Group: ESMO-ESGO-ESTRO Consensus Conference on Endometrial Cancer: Diagnosis, treatment and follow-up. Ann Oncol 27: 16-41, 2016.

2. Amant F, Moerman P, Neven P, Timmerman D, Van Limbergen E and Vergote I: Endometrial cancer. Lancet 366: 491-505, 2005.

3. van Gool IC, Eggink FA, Freeman-Mills L, Stelloo E, Marchi E, de Bruyn M, Palles C, Nout RA, de Kroon CD, Osse EM, et al: POLE proofreading mutations elicit an antitumor immune response in endometrial cancer. Clin Cancer Res 21: 3347-3355, 2015.

4. Church DN, Stelloo E, Nout RA, Valtcheva N, Depreeuw J, ter Haar N, Noske A, Amant F, Tomlinson IP, Wild PJ, et al: Prognostic significance of POLE proofreading mutations in endometrial cancer. J Natl Cancer Inst 107: 402, 2014.

5. Plante M, Touhami O, Trinh XB, Renaud MC, Sebastianelli A, Grondin K and Gregoire J: Sentinel node mapping with indocyanine green and endoscopic near-infrared fluorescence imaging in endometrial cancer. A pilot study and review of the literature. Gynecol Oncol 137: 443-447, 2015.
6. Stelloo E, Bosse T, Nout RA, MacKay HJ, Church DN, Nijman HW, Leary A, Edmondson RJ, Powell ME, Crosbie EJ, et al: Refining prognosis and identifying targetable pathways for high-risk endometrial cancer; a TransPORTEC initiative. Mod Pathol 28: 836-844, 2015.

7. Wilczynska A and Bushell M: The complexity of miRNA-mediated repression. Cell Death Differ 22: 22-33, 2015.

8. Yuan R, Zhi Q, Zhao H, Han Y, Gao L, Wang B, Kou Z, Guo Z, He S, Xue X, et al: Upregulated expression of miR-106a by DNA hypomethylation plays an oncogenic role in hepatocellular carcinoma. Tumour Biol 36: 3093-3100, 2015.

9. Yen CS, Su ZR, Lee YP, Liu IT and Yen CJ: miR-106b promotes cancer progression in hepatitis B virus-associated hepatocellular carcinoma. World J Gastroenterol 22: 5183-5192, 2016.

10. Zheng Z, Zhang Y, Zhang Z, Yang Y and Song T: Effect of miR-106b on invasiveness of pituitary adenoma via PTEN-PI3K/AKT. Med Sci Monit 23: 1277-1285, 2017.

11. Livak KJ and Schmittgen TD: Analysis of relative gene expression data using real-time quantitative PCR and the 2(-Delta Delta C(T)) Method. METHODS 25: 402-408, 2001.

12. Billingsley CC, Cohn DE, Mutch DG, Stephens JA, Suarez AA and Goodfellow PJ: Polymerase $\varepsilon$ (POLE) mutations in endometrial cancer: Clinical outcomes and implications for Lynch syndrome testing. Cancer 121: 386-394, 2015.

13. Schuler KM, Rambally BS, DiFurio MJ, Sampey BP, Gehrig PA, Makowski L and Bae-Jump VL: Antiproliferative and metabolic effects of metformin in a preoperative window clinical trial for endometrial cancer. Cancer Med 4: 161-173, 2015.

14. Mehnert JM, Panda A, Zhong H, Hirshfield K, Damare S, Lane K, Sokol L, Stein MN, Rodriguez-Rodriquez L, Kaufman HL, et al: Immune activation and response to pembrolizumab in POLE-mutant endometrial cancer. J Clin Invest 126: 2334-2340, 2016.

15. Aune D, Navarro Rosenblatt DA, Chan DS, Vingeliene S, Abar L, Vieira AR, Greenwood DC, Bandera EV and Norat T: Anthropometric factors and endometrial cancer risk: A systematic review and dose-response meta-analysis of prospective studies. Ann Oncol 26: 1635-1648, 2015.

16. Trabert B, Wentzensen N, Felix AS, Yang HP, Sherman ME and Brinton LA: Metabolic syndrome and risk of endometrial cancer in the United States: A study in the SEER-medicare linked database. Cancer Epidemiol Biomarkers Prev 24: 261-267, 2015.

17. Schnall-Levin M, Rissland OS, Johnston WK, Perrimon N, Bartel DP and Berger B: Unusually effective microRNA targeting within repeat-rich coding regions of mammalian mRNAs. Genome Res 21: 1395-1403, 2011.

18. Lin S and Gregory RI: MicroRNA biogenesis pathways in cancer. Nat Rev Cancer 15: 321-333, 2015.

19. Jonas S and Izaurralde E: Towards a molecular understanding of microRNA-mediated gene silencing. Nat Rev Genet 16: 421-433, 2015.

20. Zhang J, Li S, Li L, Li M, Guo C, Yao J and Mi S: Exosome and exosomal microRNA: Trafficking, sorting, and function. Genomics Proteomics Bioinformatics 13: 17-24, 2015.

21. Delay C, Mandemakers W and Hébert SS: MicroRNAs in Alzheimer's disease. Neurobiol Dis 46: 285-290, 2012.

22. Wang R, Li Y, Hou Y, Yang Q, Chen S, Wang X, Wang Z, Yang Y, Chen C, Wang Z, et al: The PDGF-D/miR-106a/Twist1 pathway orchestrates epithelial-mesenchymal transition in gemcitabine resistance hepatoma cells. Oncotarget 6: 7000-7010, 2015.

This work is licensed under a Creative Commons Attribution-NonCommercial-NoDerivatives 4.0 International (CC BY-NC-ND 4.0) License. 